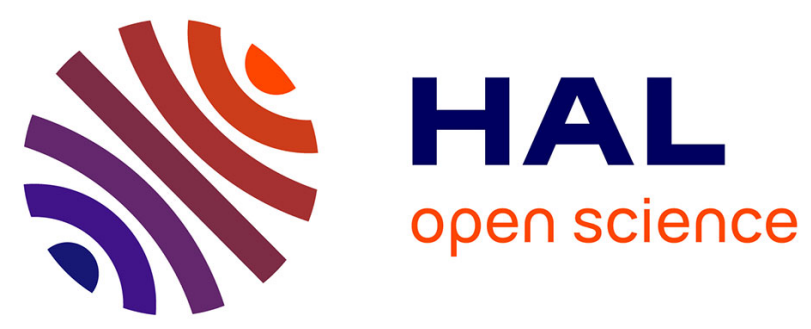

\title{
THE FINITE ELEMENT PREDICTION OF DUCTILE FRACTURE INITIATION IN DYNAMIC METALFORMING PROCESSES
}

\author{
Y. Zhu, S. Cescotto
}

\section{- To cite this version:}

Y. Zhu, S. Cescotto. THE FINITE ELEMENT PREDICTION OF DUCTILE FRACTURE INITIATION IN DYNAMIC METALFORMING PROCESSES. Journal de Physique IV Proceedings, 1991, 01 (C3), pp.C3-751-C3-757. 10.1051/jp4:19913106 • jpa-00249908

\section{HAL Id: jpa-00249908 https://hal.science/jpa-00249908}

Submitted on 1 Jan 1991

HAL is a multi-disciplinary open access archive for the deposit and dissemination of scientific research documents, whether they are published or not. The documents may come from teaching and research institutions in France or abroad, or from public or private research centers.
L'archive ouverte pluridisciplinaire HAL, est destinée au dépôt et à la diffusion de documents scientifiques de niveau recherche, publiés ou non, émanant des établissements d'enseignement et de recherche français ou étrangers, des laboratoires publics ou privés. 
Colloque C3, suppl, au Journal de Physique III, Vol. 1, octobre 1991

\title{
THE FINITE ELEMENT PREDICTION OF DUCTILE FRACTURE INITIATION IN DYNAMIC METALFORMING PROCESSES
}

\author{
Y.Y. ZHU and S. CESCOTTO \\ MSM-Institut du Génie Civil, Quai Banning, 6, B-4000 Liège, \\ Belgique
}

\begin{abstract}
Résumé - Ce papier décrit l'utilisation d'une technique non linéaire par éléments finis pour la prédiction de l'amorçage d'une rupture ductile dans la mise en forme dynamique des matériaux. La distribution locale des variables est déterminée en relation avec les états de contrainte et déformation subis par le matériau. Ces valeurs sont ensuite utilisées dans six critères de rupture précédemment publiés pour prédire les sites d'amorçage.
\end{abstract}

\begin{abstract}
This paper describes the use of nonlinear finite element technique to predict ductile fracture initation in dynamic metalforming analysis. The local distributions of variables connected. with the history of stress and strain are determined. These values are then used with six previously published fracture criteria to predict fracture initation sites.
\end{abstract}

\section{INTRODUCTION}

The initiation of ductile fracture may be the limiting factor in metalforming processes. It is important to identify the conditions within the deformed workpiece which may lead to fracture. For occurrence of cracks at the free surface, the fracture criterion can be constructed experimentally. However, for predicting internal fracture, formulations of fracture criteria under general large deformations are required.

It has long been known that plastic deformation is not the only determinant factor of the ductile fracture of metals. Plastic deformation at fracture is highly dependent on the state of stresses and strains. A modelling of the fracture criteria must be added. Many attempts have been made in the past to discover various satisfactory fracture criteria. It seems reasonable to assume that any criterion of fracture will be based on some combination of stress and strain rather than on either of these quantities separately. Knowledge of the plastic strain history prior to fracture permits the corresponding stress components to be evaluated in the usual way using the theory of plasticity. Combined stress-strain calculations may then be performed to assess various empirical mechanical criteria of fracture.

There are two types of fracture criteria (Fig.1). The first one is "macroscopic fracture criteria" or "empirical criteria", and the second one is "microscopic fracture criteria" or "criteria of void growth". The first type concentrates more on the continutum effects of the microscopic processes leading to ductile fracture and it provides a simplified condition for fracture without taking into consideration the gradual increase of internal damage during deformation of ductile materials. It requires substantial experimentation to determine the parameters required to produce a fracture prediction. It is obviously advangeous to keep the number of experimentally determined the parameters in any fracture criterion to a mininum. Therefore, those criteria which consider the continuum effects of the processes leading to ductile fracture can most easily be used in conjunction with finite element stress and strain fields. However, the more realistic fracture criteria for ductile metals belong to the second type. In this case, the process by which fractures occur in metal has been widely modelled as micro-void initation and growth followed by coalescence to form a crack. 


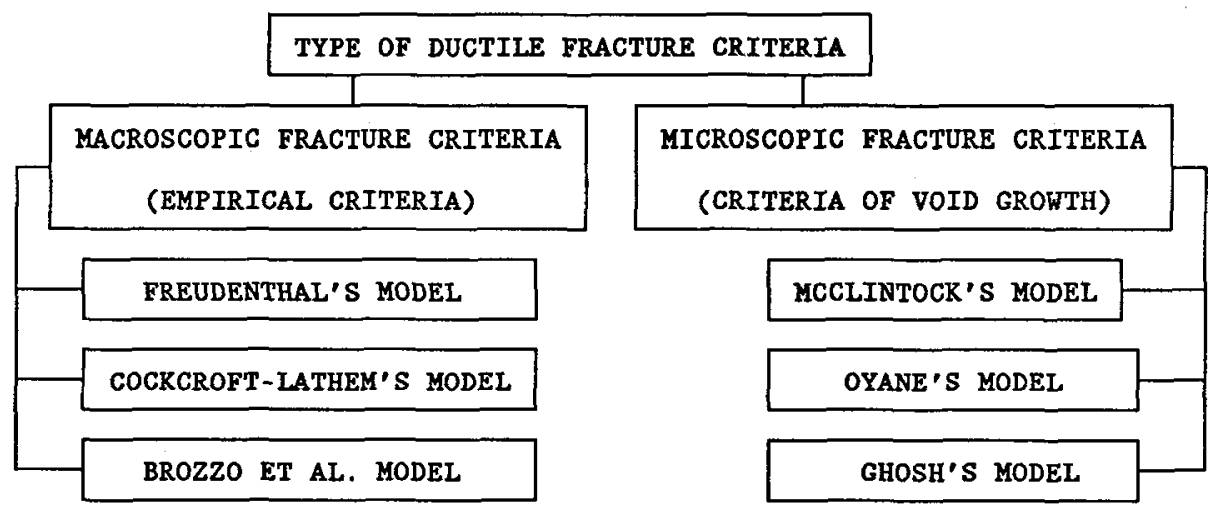

Fig. 1. Various ductile fracture criteria

Recent developments in finite element techniques for the study of metalforming problems have now made it possible to investigate in detail the predictions which can be obtained using many of these fracture criteria, and the applicable range of each criterion may be determined. Oh et al.[1] employed a rigid plastic finite element technique to examine the use of the Cockroft and Latham criterion and a modified version of the McClintock criterion to predict fracture in axisymmetric extrusion and drawing. Sowerby et al.[2], Dung[3,4] a1so used a rigid plastic finite element model to examine the capability of McClintock's vold growth model, Crockcroft and Latham criterion, and Oyane's formulation to predict damage accumulation in the upsetting of steel specimens. Their numerical results showed the McClintock's model was appropriate to assess the forgeability of certain steels. Clift et al.[5,6], Pillinger et al.[7] presented an investigation of ability of elastic-plastic finite element simulations to predict the initation of ductile fracture in bodies undergoing large plastic deformation. Several criteria have been used in conjunction with the finite element analysis. Their results pointed out that only the criterion based on generalized plastic work per unit volume was successful in predicting the site of fracture initiation for all the geometries examined.

Currently, the nonlinear finite element analysis program LAGAMINE is being developed in department M.S.M., Université de Liège, Belgium. It has been applied successfully to simulate metalforming processes in static[8] and dynamic[9] cases with very large strains, large displacements and large rotations. A special isoparametric contact element based on a penalty method and on the Coulomb dry friction law has been developed. The explicit and implicit time integration schemes have been implemented. A large number of constitutive laws have been introduced. Now six previously published fracture criteria have been implemented. The main purpose of this paper is to examine the ability of these criteria to predict fracture initation sites in dynamic metalforming processes.

\section{FRACTURE CRITERIA}

2.1 Freudenthal's mode1

Freudenthal[10] proposed that the absorbed energy per unit volume is the critical parameter at fracture, that is:

$$
\int_{0}^{\bar{\epsilon}_{\mathrm{f}}} \bar{\sigma} \mathrm{d} \bar{\epsilon}=\mathrm{Cl}
$$

where $\mathrm{C}_{1}$ is the critical material dependent value at fracture; $\bar{\sigma}$ is the generalised stress; $\bar{\epsilon}$ is the generalised plastic strain. The subscript $f$ denotes the value at fracture. This criterion does not consider the influence of hydrostatic stress and high tensile stress explicitly and sometimes it is contrary to experience. For example, in the simple tensile test, cracks are usually formed owing to high tensile stress, but this criterion predicts that neck shape should have no effects on the fracture strain directly. However, reports [5-7] pointed out that it is the simplest and best fracture criterion among all of the other criteria. 
2.2 Cockcroft-Latham's model

Cockroft and Latham[11] proposed that it is the principal tensile stress, rather than the generalised stress, which is important in fracture initiation. They postulated that fracture occurs when the integral of the largest tensile principal stress component over the plastic strain path to fracture equals a critical value for the material, namely:

$$
\int_{0}^{\bar{\epsilon}_{\mathrm{f}}} \sigma_{1} \mathrm{~d} \bar{\epsilon}=\mathrm{C} 2
$$

where $C 2$ is the critical material dependent value at fracture and $\sigma_{1}$ is the maximum principal tensile stress. This criterion does not take into account the influence of hydrostatic stress explicitly on fracture.

\subsection{Brozzo's mode1}

Brozzo et al.[12] proposed an empirical modification of Cockroft and Latham's fracture criterion to consider the effect of hydrostatic stress explicitly. The modified equation is presented in the following form:

$$
\int_{0}^{\bar{\epsilon}_{\mathrm{f}}} \frac{2 \sigma_{1}}{3\left(\sigma_{1}-\sigma_{M}\right)} \mathrm{d} \bar{\epsilon}=\mathrm{C} 3
$$
where $\mathrm{c} 3$ is the critical material dependent value at fracture and $\sigma_{M}$ is the hydro-
static stress.

\subsection{Ghosh's model}

Ghosh[13] proposed a fracture criterion for plane strain based on the statistical process of shear joining of voids in the sheet metalforming. Here, we extend it to three dimensional state, that is:

$$
\left(\sigma_{1}+\sigma_{2}+\sigma_{3}\right)\left(\sigma_{1}-\sigma_{3}\right)=C_{4}
$$

where $\mathrm{C4}$ is a material constant which is a modified form of a fracture stress parameter containing inputs from the size, volume fraction and growth rate of voids. $\sigma_{1}, \sigma_{2}, \sigma_{3}$ are three principal stresses respectively.

\subsection{Oyane's model}

Oyane et al. [14,15] consider a void growth model and postulate that

$$
\int_{0}^{\bar{\epsilon}_{f}}\left(1+\frac{\sigma_{M}}{A \bar{\sigma}}\right) d \bar{\epsilon}=\mathrm{C} 5
$$

where $C 5$ and $A$ are material constants connected with the volumetric strain to be determined from experiments.

\subsection{McClintock's model}

McClintock et al.[16] analyzed the expansion of long cylindrical cavities under a triaxial stress system of fixed orientation. They derived a closed form expression for the damage accumulation :

$$
\int_{0}^{\epsilon_{f}}\left\{\frac{2}{\sqrt{3}(1-n)} \operatorname{sh}\left[\frac{\sqrt{3}(1-n)}{2} \frac{\left(\sigma_{a}+\sigma_{b}\right)}{\bar{\sigma}}\right]+\frac{\sigma_{b}-\sigma_{a}}{\bar{\sigma}}\right\} d \bar{\epsilon}=\mathrm{c} 6
$$

where $C 6$ is the material constant, $\sigma$ and $\sigma_{\text {p }}$ principal stress components along the major and minor axes, respectively, $\mathrm{n}$ the work hardening exponent of the material which obeys the following power hardening law:

$$
\bar{\sigma}=\mathrm{K} \bar{\epsilon}^{\mathrm{n}}
$$

There are two other equations for the coalescence of holes with their axes paralle1 to the other principal axes. This criterion is more valid for fracture in the solid subject to high triaxial tensile stresses.

\section{EQUATION OF MOTION AND ITS TIME INTEGRATION}

\subsection{Equation of Motion}

The general formula of the incremental finite element equation of motion using the principle of virtual displacement is

$$
\text { [M] }(\ddot{U})+[C](\dot{U})=\left(F^{\text {ext }}\right)-\left(F^{\text {int }}\right)
$$


where,

$\{\ddot{U}\},\{\dot{U}\}=$ vectors of nodal accelerations and velocities respectively
$[M] ; t[C]=$ mass and damping matrices respectively
$\left\{F_{i n t}\right\}=$ vector of equivalent nodal forces due to external loads
$\left\{F^{\text {int }}=\right.$ vector of equivalent nodal forces due to internal element stresses The internal stresses include the contributions of not only the classical isoparametric 2D, axisymmetric and 3D elements but also of the isoparametric contact finite elements.

Equation of motion (8) must clearly be integrated forward in time to produce the dynamic response. Both explicit and implicit time integration methods may be employed for this purpose.

\subsection{Explicit Time Integration}

According to the central difference formulae:

$$
\begin{aligned}
& \{\mathrm{U}\}_{\mathrm{N}+1}=\{\mathrm{U}\}_{\mathrm{N}}+\Delta t_{\mathrm{N}}\{\dot{\mathrm{U}}\}_{\mathrm{N}}+\frac{\Delta \mathrm{t}_{\mathrm{N}}^{2}}{2}\{\ddot{\mathrm{U}}\}_{\mathrm{N}} \\
& \{\dot{\mathrm{U}}\}_{\mathrm{N}+1}=\{\dot{\mathrm{U}}\}_{\mathrm{N}}+\frac{\Delta t_{\mathrm{N}}}{2}\{\dot{\mathrm{U}}\}_{\mathrm{N}}+\frac{\Delta t_{\mathrm{N}}}{2}\{\ddot{\mathrm{U}}\}_{\mathrm{N}+1}
\end{aligned}
$$

Here, $N$ denotes the time step number, $\Delta t_{N}$ being the time increment between $t_{N}$ and $t_{N}+\Delta t_{N}$. If the response is strongly non-1inear, the central difference method should be used with a variable time increment $\Delta t$ for numerical stability. After each time step, a new time increment $\Delta t_{N}$ is established from the current stability criterion

$$
\Delta \mathrm{t}_{\mathrm{N}}=\min \left\{\mu \mathrm{L}^{\mathrm{K}} \sqrt{\frac{\rho(1+\nu)(1-2 \nu)}{\mathrm{E}(1-\nu)}} \text {, to each element }\right\}
$$

where the stability factor $\mu$ is taken to be 0.5 for 2D analysis 0.3 for 3D analysis; L is the smallest distance between adjacent nodes of any element with the same material; E is elastic modulus; $\nu$ is Poisson's ratio; $\rho$ is the mass density.

Substituting equations (9)-(10) into equation (8), lumping consistant matrix ${ }^{\text {ma] }}$

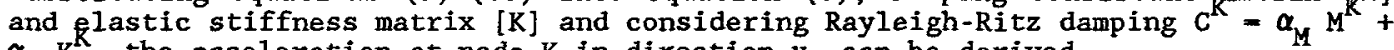
$\alpha_{\mathrm{K}} \mathrm{K}$, the acceleration at node $\mathrm{K}$ in direction $\mathrm{x}_{\hat{1}}$ can be derived.

\subsection{Implicit Time Integration}

For implicit time integration, equation (8) is usually written as follows :

$$
\{R\}_{N+1}=[M]\{\ddot{U}\}_{N+1}+[C]\{\dot{U}\}_{N+1}-\left\{F^{\text {ext }}\right\}_{N+1}+\left\{F^{\text {int }}\right\}_{N+1}=\{0\}
$$

where $(R)$ is the so-called out-of-balance force. The Newmark integration scheme consists $\mathrm{N}^{1}$ following difference fomulae

$$
\begin{aligned}
&\{\mathrm{U}\}_{\mathrm{N}+1}=\{\mathrm{U}\}_{\mathrm{N}}+\Delta t_{\mathrm{N}}\{\dot{\mathrm{U}}\}_{\mathrm{N}}+\frac{1}{2} \Delta t_{\mathrm{N}}^{2}\left[(1-2 \beta)\{\ddot{\mathrm{U}}\}_{\mathrm{N}}+2 \beta\{\ddot{\mathrm{U}}\}_{\mathrm{N}+1}\right] \\
&\dot{\mathrm{U}}\}_{\mathrm{N}+1}=\{\dot{\mathrm{U}}\}_{\mathrm{N}}+\Delta t_{\mathrm{N}}\left[(1-\gamma)\{\ddot{\mathrm{U}}\}_{\mathrm{N}}+\gamma\{\ddot{\mathrm{U}}\}_{\mathrm{N}+1}\right]
\end{aligned}
$$

In order to satisfy the discretized equations for the displacement (U) $N+1$, an equilibrium iteration sequence $(p=1,2, \ldots)$ is required. The tangent matrix is

$$
[\mathrm{K}]_{\mathrm{N}+1}^{\mathrm{p}}=\left.\frac{\partial\{\mathrm{R}\}}{\partial\{\mathrm{u}\}}\right|_{\{\mathrm{u}\}} ^{\mathrm{p}}{ }_{\mathrm{N}+1}
$$

\section{RESULTS AND DISCUSSIONS}

By using the finite element program LAGAMINE connected with the fracture criteria mentioned above, numerical predictions of the fracture initiation sites are obtained, thanks to the accumulative values of each fracture criterion found at each Gauss integration point of the finite element mesh.

As an attractive example, let us consider a dynamic modelling of forging of steel at $1150^{\circ} \mathrm{C}$. High strain rates and large variations of the contact area are effective in this example. The material properties of workpiece are assumed to be represented by an elastic-visco-plastic constitutive equation in which all the parameters are determined according to the temperature: Young's elastic modulus $\mathrm{E}=1.2 \times 10^{5} \mathrm{MPa}$; Poisson's ratio $\nu=0.4$; strain rate exponent $\mathrm{n}=9.259$; strain rate coefficient $\mathrm{B}=0.034$; initial yield limit $\mathrm{K}_{0}=50 \mathrm{MPa}$; mass density $\rho=7800 \mathrm{~kg} / \mathrm{m}^{3}$. For definition of contact element, the penalty coefficient on the contact pressure and 
on the shear frictional stress $\mathrm{K}_{2}, \mathrm{~K}_{2}=5 \times 10^{13} \mathrm{~N} / \mathrm{m}$, the penalty coefficient $=5 \times 10^{13}$ $\mathrm{N} / \mathrm{m}$, and the Coulomb's friction $\mathrm{Coef}^{\prime}$ icient $\phi=0.3$ are chosen.

This simulation corresponds to a practical case of metalforming in which a fracture was observed during the forming process. Althought the actual piece was three dimensional, the region in which the crack developed could be adequately modelled as axisymmetric (Fig.2). Furthermore, due to the existence of an horizontal plane of symmetry, only one half of the piece is discretized.

Since the strains are very large, the choice of an appropriate initial finite element mesh becomes a very important aspect. In fact, it is necessary to make sure that the simulation results are practically mesh independent. Therefore, three different meshes are used (shown Fig.4): "MESHI" 6-nodes finite elements with constant mesh density; "MESH2" 6-nodes finite elements with variable mesh density; "MESH3" 8-nodes finite elements with variable mesh density. The time curve of imposed displacement of the upper die is described Fig.3. The initial velocity-7m/s and initial acceleration $1926.1 \mathrm{~m} / \mathrm{s}^{2}$ of the die are selected in order to satisfy the continuity condition.

Fig.4 shows the initial meshes (solid line) together with corresponding deformed configurations (dashed line) at time $t=0.5 \mathrm{~ms}$ obtained by static, implicit or explicit dynamic formulae. At this time, fracture initiation sites of workpiece near the corner of the die can be observed experimentally. On Fig. 4 we can observe that the element near the right corner of the die are severely distorted. This means that the finite element mesh should be refined in the region of the flash and that the solution presented on Fig.4 does not model the flash with precision. However, we are more interested in the region near the left re-entrant corner of the die, where the mesh is not too distorted. All the numerical simulation show that the accumulative values of the six fracture criteria present a very sharp maximum near this corner at time $t=0.5 \mathrm{~ms}$. These values are given in table 1 . The location of these maxima are indicated by a cross on Fig.5 (the results given by implicit simulation of MESH 3). On the same figures, other crosses appear, in the flash region. These mean that the accumulative values at these Gauss integration points are equal or larger than that at the point near the left corner. Hence, in the flash, there are some points at which the critical value is larger than at the point near the left corner of the die. However the flash will be cut off at the end of the forging process. Furthermore, it was pointed out that the solution in the flash is not reliable because of the excessive mesh distorsion.

Table 1 shows the wide agreement of accumulative values of each criterion given by different meshes, different time integration schemes. The differences may be due to the discretizations. Fig.5 indicate that the fracture initiation locations based on each criterion are almost the same, and the damage accumulations are very local near the left corner of the die which is identical to the experimental results. This may be due to the existence of high stress concentrations and the localization of strains near the corners.

Table 1.

\begin{tabular}{|c|c|c|c|c|c|c|c|}
\hline \multicolumn{2}{|c|}{ criteria } & 1 & 2 & 3 & 4 & 5 & 6 \\
\hline mesh1 & implicit & 8.84 & 2.03 & 1.23 & 4.02 & 0.45 & 3.16 \\
\hline \multirow{2}{*}{ mesh2 } & imp1icit & 6.85 & 1.12 & 0.70 & 20.1 & 0.29 & 2.51 \\
\cline { 2 - 8 } & exp1icit & 7.05 & 1.22 & 0.76 & 20.2 & 0.32 & 2.63 \\
\hline mesh2 & implicit & 9.17 & 0.91 & 0.66 & 16.0 & 0.27 & 3.31 \\
\hline
\end{tabular}

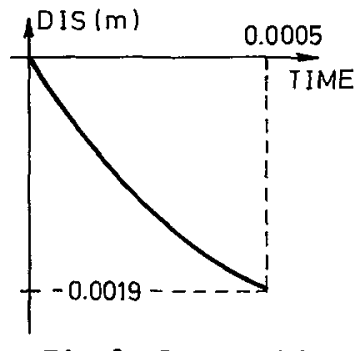

Fig.2 Dep. - Time

CONCLUSIONS-In this paper the numerical analysis for dynamic metalforming has been presented. The numerical results produced by finite element analysis have been used to give predictions of fracture initation site for six previously published fracture criteria. According to the given numerical example we can conclude that irrespective of the type of meshes and time integration schemes, the critical accumulative damage of each criterion is almost constant; regardless of the kind of criteria the fracture initiation occurs at the same location which agrees with the observation of the experiment. Therefore, the fracture criteria may be appropriate to assess some metalforming processes. 


\section{REFERENCES}

$11 /$ S.L. Oh et al., Transactions of the ASME 101 (1979) 36

$/ 2 / R$. Sowerby et al., VDI-Forschung im Ingenieurwesen 51 (1985)

$13 / \mathrm{N} . \mathrm{L}$. Dung, Proc. of Int. Conf. MUMIFORM 86, Goteborg (1986)

$/ 4 / \mathrm{N}$. L. Dung, Advance of plasticity in 1989

/5/S.E. Clift, et al. Proc 25th MTDR conference, (1885) 413

/6/S.E. Clift, et al. Int. J. Mech. Sci. 32 (1990) 1

/7/I. Pillinger et al., Inter. J. for Numer. Meth. in Engineering, 25 (1988) 87

$/ 8 / R$. Charlier \& S. Cescotto, Jounal de Mecanique Theorique et appliquee, 7 (1988)

/9/S. Cescotto \& Y. Zhu, Euro. Conf. on new advance in Compu. Stru. Mech., (1991)

/10/A.M. Freudentha1, "The inelastic behaviour of engineering materials and structures", Wiley, New York, 1950.

/11/M.G. Cockroft and D.J. Latham, J. Inst. Metals, 96 (1976) 33

/12/P. Brozzo et al. Proc. 7th biennial Conf. (1972)

/13/A.K. Ghosh, Metallurgical Transactions 7 (1976) 523

$/ 14 /$ M. Oyane, Bulletin of the JSME 15 (1972) 1507

$/ 15 / \mathrm{M}$. Oyane et a1. J. Mech. Work. Tech. 4 (1980) 65

/16/F.A. McClintock, J. App1. Mech. 35 (1968) 363

$/ 17 / \mathrm{S}$. Cescotto \& R. Charliex, SMIRT-8 (1985)
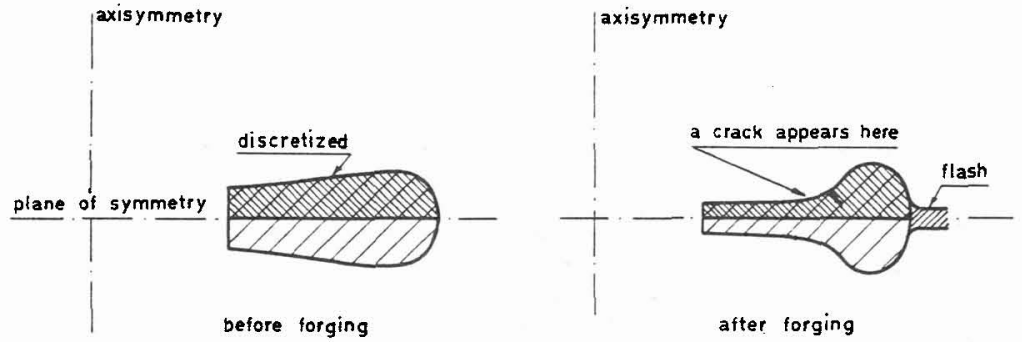

Fig. 3

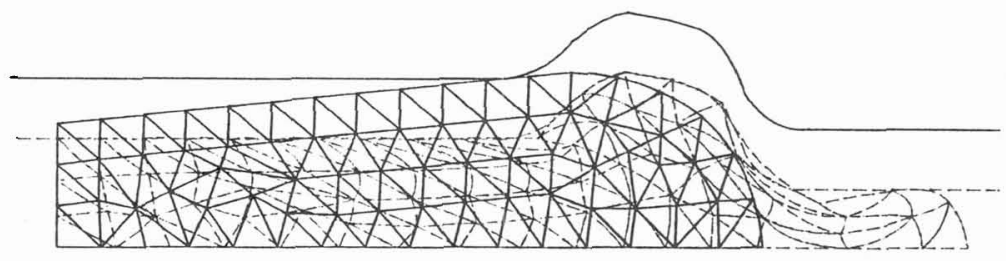

(a) mesh 1

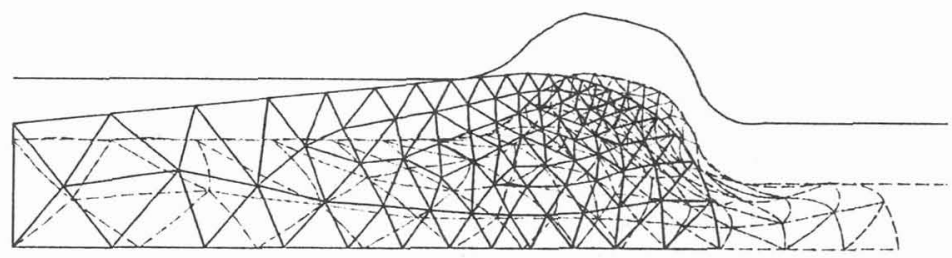

(b) mesh 2

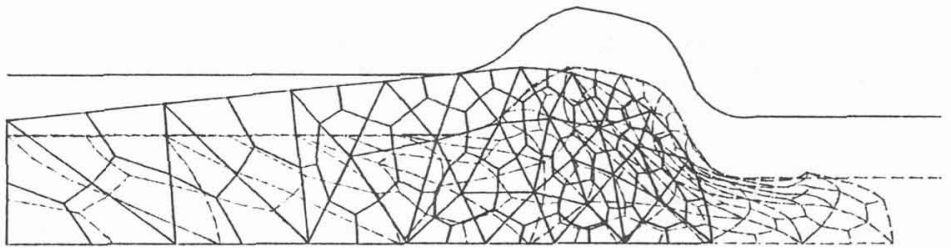

(c) mesh 3

FIg.4 Mesh and deformation 


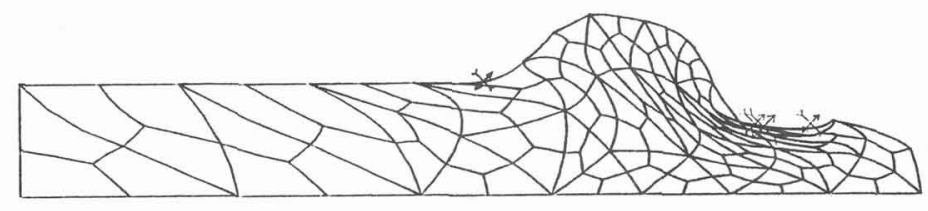

(a) criterion-1

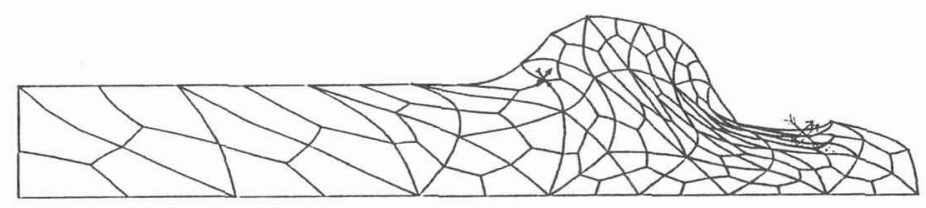

(b) criterion-2

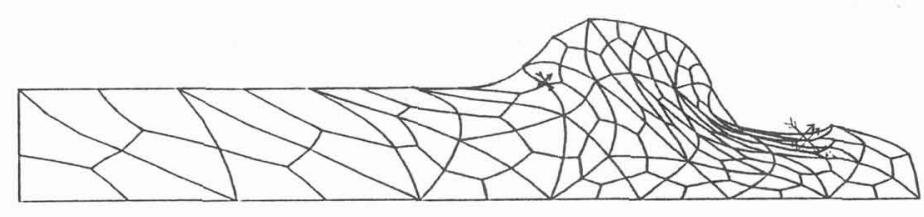

(c) criterion-3

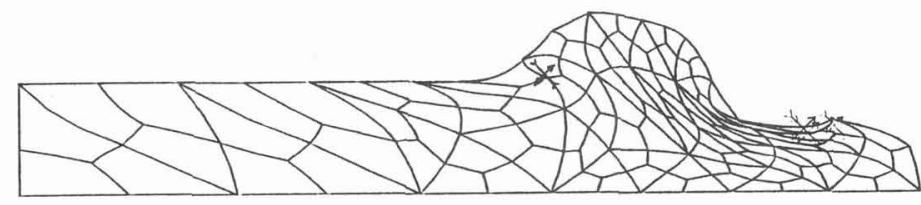

(d) criterion- 4

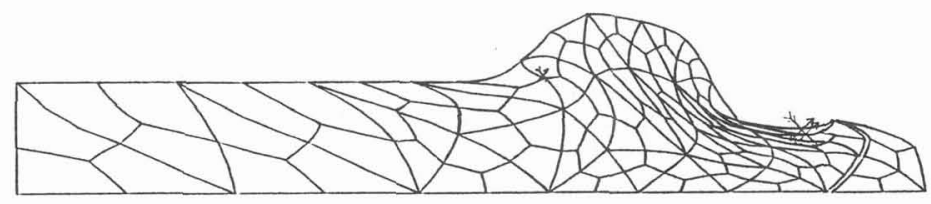

(e) criterion-5

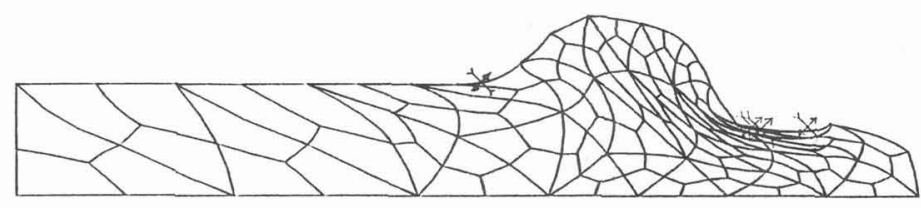

(f) criterion-6

Fig. 5 fracture criteria for mesh 3 